of natural thyrsiferyl 23 -acetate $(3)^{32}\left([\alpha]^{23}{ }_{220}+250^{\circ},[\alpha]^{23}{ }_{300}+27^{\circ}\right.$ (c $0.02, \mathrm{MeOH})$ ).

Acknowledgment. We are most grateful to Prof. Etsuro Kurosawa and Dr. Teruaki Suzuki (Hokkaido Univ.) for the generous gift of samples of thyrsiferol (1), thyrsiferyl 23 -acetate $(3)$, and $\Delta^{15,16}$-anhydrothyrsiferyl diacetate and to Prof. Tatsuo Higa (Ryukyu Univ.) for the spectral data of venustatriol (5).

Supplementary Material Available: ${ }^{1} \mathrm{H}$ NMR spectra of $1,3,5,10,12-15,19-31,34,36-43,45,47,49-54,56-58,62-73$, 75-80, 83-92, 94, and 96-99 and ${ }^{13} \mathrm{C}$ NMR spectrum of 45 (78 pages). Ordering information is given on any current masthead page.

\title{
Lucidene, a Bis(benzopyranyl) Sesquiterpene from Uvaria lucida ssp. lucida
}

\author{
Hugo Weenen ${ }^{\dagger}$ and Mayunga H. H. Nkunya* \\ Department of Chemistry, University of Dar es Salaam, P.O. Box 35061, Dar es Salaam, Tanzania
}

A. Adul El-Fadl ${ }^{\ddagger}$ and Sybolt Harkema

Chemical Physics Laboratory, University of Twente, P.O. Box 217, 2500 AE Enschede, The Netherlands

Binne Zwanenburg

Department of Organic Chemistry, University of Nijmegen, Toernooiveld, 6525 ED Nijmegen, The Netherlands

Received November 27, 1989

\begin{abstract}
Lucidene (1), a bis(benzopyranyl) sesquiterpene was isolated from the rootbark of Uvaria lucida ssp. lucida, and its structure was determined by spectroscopic methods and single-crystal X-ray crystallography. It is optically inactive and crystallizes in enantiomeric pairs. High-resolution ${ }^{1} \mathrm{H}$ NMR $(400$ and $600 \mathrm{MHz}$ ) spectroscopy allowed the assignment of all protons and indicated the existence of relatively slowly interconverting conformations. The three known dihydrochalcones, uvaretin, diuvaretin, and chamuvaretin, as well as benzyl benzoate were isolated from the same plant as well.
\end{abstract}

\section{Introduction}

Uvaria species have been a source of several new compounds, ${ }^{1,2}$ some with cytotoxic, ${ }^{3}$ antimicrobial, ${ }^{4}$ and antimalarial ${ }^{5}$ activity. A typical structural feature that occurs frequently in compounds isolated from Uvaria species is the presence of benzyl or o-hydroxybenzyl groups, as in the uvaretins ${ }^{3,6}$ and some indoles. ${ }^{7,8}$ Sesquiterpenes containing $o$-hydroxylbenzyl groups occur in Uvaria species as well, and three such compounds have thus far been reported. ${ }^{9}$ In this paper we describe the determination of the structure of a new sesquiterpene, viz. a bis(benzopyranyl) sesquiterpene, which we have named lucidene (1). The present investigation was carried out as part of our project on antimalarial constituents of Uvaria species. Lucidene was isolated from the petroleum ether extract of the rootbark of Uvaria lucida spp. lucida, which showed relatively high in vitro activity against the multidrug resistant $\mathrm{K}_{1}$ strain of Plasmodium falciparum; however, lucidene itself showed no such activity. ${ }^{10}$

\section{Results and Discussion}

The title compound (1) was isolated from the petroleum ether extract of the rootbark of Uvaria lucida using gradient silica gel chromatography (hexane/ethyl acetate), in addition to the known compounds benzyl benzoate, ${ }^{8}$ chamuvaretin, 8,11 uvaretin, ${ }^{3,8}$ and diuvaretin. ${ }^{3,8}$

Lucidene (1), which was recrystallized from hexane, showed a mass spectrum with characteristic ions at $m / e$ $416\left(\mathrm{M}^{+}\right.$), 309 (monooxybenzyl sesquiterpene: $\mathrm{M}^{+}-$hy-

\footnotetext{
* To whom correspondence should be addressed.

tPresent address: Quest International, P.O. Box 2, $1400 \mathrm{CA}$ Bussum, The Netherlands.

Present address: Physics Department, Faculty of Science, Assiut University, Assiut, Egypt.
}

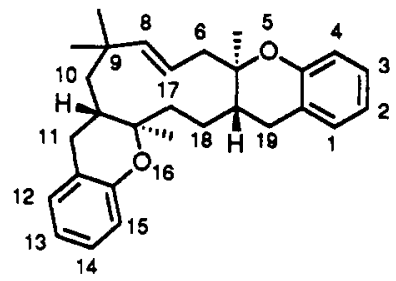

1

droxybenzyl) and 107 (o-hydroxybenzyl). The high-resolution MS showed the $\mathrm{M}^{+}$at $m / z 416.2720$, which corresponds with $\mathrm{C}_{29} \mathrm{H}_{36} \mathrm{O}_{2}$ (calcd 416.2715). These mass spectral data suggest for 1 a sesquiterpene structure containing two oxybenzyl fragments.

The UV ( $\lambda_{\max }$ (hexane) $284,277,228,220 \mathrm{~nm}$ ) and IR spectra $(\mathrm{KBr}, 1610,1584(\mathrm{C}=\mathrm{C}), 1262,1246,1235,1221$ (C-O), 760 , and $753 \mathrm{~cm}^{-1}$ (ortho-substituted phenyl)) suggest the presence of two benzopyran moieties in 1 .

Since it was not possible to fully characterize compound 1 with the available spectral data $\left(400-\right.$ and $600-\mathrm{MHz}^{1} \mathrm{H}$ NMR, UV, IR, and MS), single-crystal X-ray diffraction

(1) Leboeuf, M.; Cavê, A.; Bhaumik, P. K.; Mukherjee, B.; Mukherjee, R. Phytochemistry 1982, 21, 2783. 84.

(2) Thebtaranonth, C.; Thebtaranonth, Y. Acc. Chem. Res. 1986, 19,

(3) Lasswell, W. L., Jr.; Hufford, C. D. J. Org. Chem. 1977, 42, 1295.

(4) Hufford, C. D.; Lasswell, W. L., Jr. Lloydia 1978, 41, 156.

(5) Nkunya, M. H. H.; Weenen, H.; Koyi, N. J.; Thijs, L.; Zwanenburg,

B. Phytochemistry 1987, 26, 2563.

(6) Nkunya, M. H. H.; Achenbach, H.; Renner, C.; Weenen, H., submitted to Phytochemistry.

(7) Waterman, P. G.; Muhammad, I. J. Chem. Soc., Chem. Commun. 1984, 1280.

(8) Muhammad, I.; Waterman, P. G. J. Nat. Prod. 1985, 48, 571.

(9) Muhammad, I.; Waterman, P. G. J. Nat. Prod. 1988, 51, 719.

(10) Nkunya, M. H. H.; Weenen, H.; Bray, D. H., submitted to Planta Medica.

(11) Okorie, D. A. Phytochemistry 1977, 16, 1591. 


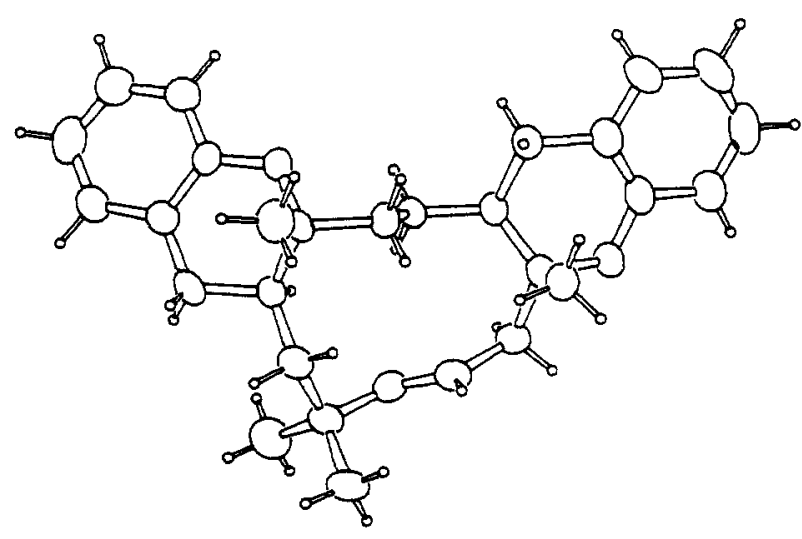

Figure 1.

analysis was carried out. This analysis reveals the presence of two enantiomers, one of which has the structure depicted in Figure 1.

The ${ }^{1} \mathrm{H}$ NMR spectrum of 1 taken at $298 \mathrm{~K}$ indicates the presence of two ortho-substituted phenyl rings, four methyl groups which appear as singlets, and several methylene and methine protons. Some very broad peaks were observed in the aliphatic region, which were initially contributed to impurities. However, the molecular structure determined by the X-ray analysis pointed to a different interpretation, viz. that these very broad signals may be attributed to slowly interconverting conformations of the undecene ring. This was confirmed by taking the ${ }^{1} \mathrm{H}$ NMR spectrum at $328 \mathrm{~K}$, whereby significant sharpening of all broad peaks occurred. At that temperature, the multiplicity of all peaks could be established, except for the signal at $\delta 2.05(\delta 208$ at $298 \mathrm{~K})$, which was still rather broad. The assignment of most signals, as well as their multiplicity and $J$ values, were mainly determined by single-frequency decoupling experiments (see Table I). For example, the methine proton at C-10A ( $\delta 1.96)$ appears as a ddd $(J=11,5.5,5.5 \mathrm{~Hz})$ but actually is a dddd, because decoupling of the signal at $1.55(\mathrm{H}-10 \alpha)$ clearly caused line sharpening $(J \sim 1 \mathrm{~Hz})$. The methine proton at C-19A $(\delta 2.22, \mathrm{~m})$ is structurally very similar to the proton at C-10A, but it is shifted downfield by approximately $0.2 \mathrm{ppm}$ and shows somewhat different coupling constants. Protons at C-6, C-7, and C-8 show a relatively simple ABX pattern, with both protons at C-6 appearing as a single doublet $(J=7.5 \mathrm{~Hz})$ instead of the expected $\mathrm{AB}$ system. The $\mathrm{C}-10 \beta$ proton resonates at relatively high field $(\delta 1.08$, dd, $J=16,7.5,7.5 \mathrm{~Hz}$ ), almost hidden under a methyl peak with the same chemical shift. Decoupling of the C-10 $\alpha$ proton, however, clearly revealed its multiplicity, and its coupling with $\mathrm{H}-10 \beta(\mathrm{J}=16 \mathrm{~Hz})$. Inspection of molecular models suggests that the relatively high field position of $\mathrm{H}-10 \beta$ is possibly due to an anisotropic effect of the C-7-C-8 double bond.

The most striking phenomenon in the ${ }^{1} \mathrm{H}$ NMR spectra, however, is the remarkable peak sharpening at $328 \mathrm{~K}$, in comparison with $298 \mathrm{~K}$. The two benzopyran moieties apparently decrease the flexibility of the undecene ring system, thereby slowing down conformational interconversion. Some of the signals that are broad in the $600-\mathrm{MHz}$ ${ }^{1} \mathrm{H}$ NMR spectrum appear slightly sharper in the $400-\mathrm{MHz}$ spectrum at the same temperature, since the coalescence temperature is dependent on $\left|\nu_{\alpha}-v_{\beta}\right|$. The C-19 methylene proton at $\delta 2.08$ in the $298 \mathrm{~K}$ spectrum, is the only proton that still gives a broad signal $(\delta 2.05)$ at $328 \mathrm{~K}$. This implies that the chemical shift of this proton differs significantly more when going from one conformation to another $\left(\left|v_{\alpha}-v_{\beta}\right|\right)$ than the chemical shifts of all other protons.
Table I. 'H NMR (600 MHz) Spectral Data for Lucidene

\begin{tabular}{|c|c|c|c|c|}
\hline \multicolumn{3}{|r|}{$298 \mathrm{~K}$} & \multicolumn{2}{|r|}{$328 \mathrm{~K}^{a}$} \\
\hline $\mathrm{H}$ & $\delta$ & multiplicity, $J(\mathrm{~Hz})$ & $\delta$ & multiplicity, $J(\mathrm{~Hz})$ \\
\hline 6 & 2.56 & $\mathrm{~d}, 7.5(2 \mathrm{H})$ & & \\
\hline 7 & 5.63 & ddd, $16,7.5,7.5$ & & \\
\hline 8 & 5.73 & $\mathrm{~d}, 16$ & & \\
\hline & $\begin{array}{l}1.55 \\
1.08\end{array}$ & $\begin{array}{l}\mathrm{d}, 14,1.5 \\
\mathrm{dd}, 14,5.5\end{array}$ & & \\
\hline $10 \mathrm{~A}$ & 1.96 & $\begin{array}{l}\text { dddd, } 11,5.5,5.5 \\
\quad 1.5\end{array}$ & & \\
\hline $11 \alpha$ & 2.56 & $\mathrm{dd}, 16,11$ & & \\
\hline $11 \beta$ & 2.79 & $\mathrm{dd}, 16,5.5$ & & \\
\hline 17 & $\begin{array}{l}1.69 \\
1.81\end{array}$ & $\begin{array}{l}\text { br } m \\
\text { br m }\end{array}$ & $\begin{array}{l}1.72 \\
1.88\end{array}$ & $\begin{array}{l}\text { ddd, } 13,13,3.5 \\
\text { ddd, } 13,13,3.5\end{array}$ \\
\hline 18 & $\begin{array}{l}1.81 \\
2.08\end{array}$ & $\begin{array}{l}\text { br m } \\
\text { v br s }\end{array}$ & $\begin{array}{l}1.82 \\
2.05\end{array}$ & $\begin{array}{l}\text { dddd, } 12,12,4.5,4.5 \\
\text { br m, }\end{array}$ \\
\hline $18 \mathrm{~A}$ & 2.22 & $\mathrm{~m}$ & 2.22 & dddd, $13.5,4.5,4.5,4.5$ \\
\hline $19 \alpha$ & 2.79 & brd & 2.79 & $\mathrm{dd}, 16,13.5$ \\
\hline & 2.67 & br d & 2.69 & $\mathrm{dd}, 16,4.5$ \\
\hline $5 \mathrm{~A}-\mathrm{Me}$ & 1.25 & $\mathrm{~s}$ & & \\
\hline $16 \mathrm{~A}-\mathrm{Me}$ & 1.25 & $\mathrm{~s}$ & & \\
\hline 9-Me & 1.08 & $\mathrm{~s}$ & & \\
\hline & 1.12 & s & & \\
\hline Ar-H's & 7.04 & $t, 7.5(2 \mathrm{H})$ & & \\
\hline & 7.03 & $\mathrm{~d}, 7.5$ & & \\
\hline & 6.97 & $\mathrm{~d}, 7.5$ & & \\
\hline & 6.80 & $\mathrm{t}, 7.5$ & & \\
\hline & 6.74 & $t, 7.5$ & & \\
\hline & b. & & & \\
\hline
\end{tabular}

anly signals which had significantly sharpened in comparison with the spectrum at $298 \mathrm{~K}$ were included.

Molecular models of the most likely conformations suggest that in one conformation the proton at C-19 is in the vicinity of the $\pi$ system of the C-7, C-8 double bond, while in another this is not the case. Apparently, the anisotropic effect of the double bond is rather strong and responsible for the broadness of the signal at $\delta 2.08$.

In the ${ }^{13} \mathrm{C}$ NMR spectrum a similar phenomenon was observed. Six signals for aliphatic carbons were broad at $298 \mathrm{~K}$ and sharpened to a varying degree when the temperature was raised to $328 \mathrm{~K}$. In addition, there was also a signal $(\delta 124.5)$ in the $\mathrm{sp}^{2}$ region which was very sharp at $328 \mathrm{~K}$, but quite broad at $298 \mathrm{~K}$. The ${ }^{13} \mathrm{C}$ NMR spectrum showed only 13 signals in the $\mathrm{sp}^{2}$ region, instead of the expected 14. Apparently two signals have identical chemical shifts.

GC-MS analysis of the least polar chromatography fractions of the hexane extract of $U$. lucida ssp. lucida showed the presence of the known sesquiterpenes cyperene (39.3\% of the combined nonpolar fractions, according to peak integration by GC), $\beta$-selinene $(17.9 \%), \alpha$-selinene $(5.5 \%)$, humulene $(<1 \%)$, and several other constituents, which were either present in very small concentration or unknown. Four unidentified sesquiterpenes $(1.3 \%)$ showed the characteristic fragmentation pattern of sesquiterpenes with an oxybenzyl moiety ( $\mathrm{m} / \mathrm{e} 310$ and 107$)$.

Lucidene (1) can be considered as an addition product of humulene (2), which was also present in the least polar fractions of the rootbark extract (vide supra). The observation that lucidene was isolated as a racemic mixture suggests a biosynthetic formation by a nonenzymatic pathway. In fact a conceivable formation of lucidene is a double Diels-Alder reaction of humulene with two molecules of 0 -benzoquinone methide (3). Apart from

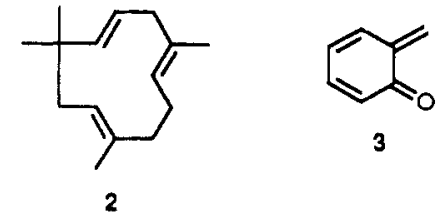


reacting as a dienophile in Diels-Alder reactions, obenzoquinone methide (3) can also undergo Michael conjugate addition reactions to produce 0 -hydroxybenzyl entities. Diels-Alder type products of terpenoids, as well as o-hydroxybenzyl-containing compounds, are well known among Uvaria metabolites. ${ }^{6,7,12}$ The three dihydrochalcones isolated by us from the same plant, uvaretin, diuvaretin, and chamuvaretin, are also metabolites containing $o$-hydroxybenzyl fragments.

The question whether other diastereomers (ring junction methyls trans) and regioisomers (oxygen of o-quinone methide bonded to less substituted carbon in cycloadduct) are formed as well cannot be answered here, since small quantities of such compounds may have remained undetected.

\section{Experimental Section}

The melting points were determined on a "Electrothermal melting point apparatus", and are uncorrected. Mass spectra were taken with a Varian MAT 311a spectrometer and GC-MS with a VG MM7070F mass spectrometer using a $25 \mathrm{~m}$ CP-Sil 19CB column. ' $\mathrm{H}$ NMR spectra were taken at 400 and $600 \mathrm{MHz}$ (Bruker AM400 and AM600). All NMR spectra were taken in $\mathrm{CDCl}_{3}$, using TMS as an internal standard. Infrared spectra were taken with a Perkin-Elmer 257 spectrophotometer and ultraviolet spectra with a Unicam SP. 800 .

Isolation Procedures. The plant material used in this study was obtained from Chalinze, Tanzania, and identified by Mr. L. B. Mwasumbi, Department of Botany, University of Dar es Salaam. A voucher specimen was deposited at the Herbarium of the Department of Botany, University of Dar es Salaam.

The dried ground rootbark ( $385 \mathrm{~g}$ ) of $U$. lucida ssp. lucida was extracted with petroleum ether $\left(\mathrm{bp} 60-80^{\circ} \mathrm{C}\right)$ and fractionated by gravitational chromatography (silica gel) using a hexane/ethyl acetate gradient. The first fraction $(9.4 \mathrm{~g})$ contained mostly sesquiterpenes, and was analyzed by GC-MS. Subsequent fractions yielded, in order of elution: lucidene, benzyl benzoate, chamuvaretin, uvaretin, and diuvaretin.

Lucidene $(5 a, 6,9,10,10 a, 16 a, 17,18,18 a, 19$-Decahydro4a,9,9,16a-tetramethyl-11 $H$-cycloundeca[ $[1,2-b: 5,6-b]$ bis $[1]-$ benzopyran). Recrystallization from hexane yielded $55 \mathrm{mg}$ of pure lucidene, as white crystals: $m p 208-210^{\circ} \mathrm{C}$; UV $\lambda_{\max }(n-$ hexane) $284 \mathrm{~nm}\left(\epsilon 3.523 \times 10^{3}\right), 277\left(\epsilon 3.09 \times 10^{3}\right), 228(\epsilon 1.30 \times$ $\left.10^{4}\right)$, and $220\left(\epsilon 1.52 \times 10^{4}\right)$; IR $(\mathrm{KBr}) 1610$ and $1584(\mathrm{C}=\mathrm{C}), 1487$ and $1455(\mathrm{C}-\mathrm{H}), 1262,1246,1235$, and $1221(\mathrm{C}-\mathrm{O})$, and 760 and $753 \mathrm{~cm}^{-1}$ (ortho-substituted phenyl group); mass spectrum (EI) $m / e$ (rel abundance) $416\left(\mathrm{M}^{+}, 35\right), 309\left(\mathrm{M}-\mathrm{CH}_{2} \mathrm{PhOH}, 50\right), 198$ (32), 171 (35), 159 (100), $158(63), 145(24)$, and $107\left(\mathrm{PhOHCH}_{2}{ }^{+}\right.$, 64); calculated for $\mathrm{C}_{29} \mathrm{H}_{36} \mathrm{O}_{2} 416.2715$, found 416.2720. The compound turned brown with anisaldhyde on TLC and was found to be a racemic mixture by X-ray analysis. ${ }^{1} \mathrm{H}$ NMR data are collected in Table I. ${ }^{13} \mathrm{C}$ NMR ( $\mathrm{CDCl}_{3}, 298 \mathrm{~K}, 100.6 \mathrm{MHz}$, signals indicated with an asterisk $\left({ }^{*}\right)$ significantly sharpened when the temperature was raised to $328 \mathrm{~K}$ ): $19.67,21.34,23.64^{*}, 26.60^{*}$,

(12) Nkunya, M. H. H.; Achenbach, H.; Renner, C.; Weenen, H.; Waibel, R., submitted to Phytochemistry.

(13) Stahl, E., Dünnschichtchromatographie, 2nd ed.; Springer Verlag: Berlin, 1967
$29.09,29.69,30.00,31.77 * 32.64,35.75^{*}, 40.85^{*}, 46.07,49.02 *, 79.46$, $79.72,116.66,117.20,119.30,119.66,121.69,122.87,124.50 *, 127.08$, $127.31,128.73,129.15,143.97,153.53$

Chamuvaretin. The semipurified fraction containing chamuvaretin was further purified by column chromatography (fractogel, PVA 500), using acetone as the eluent, and by PTLC. Yield: $35 \mathrm{mg}, \mathrm{MS},{ }^{1} \mathrm{H}$ NMR, UV, and IR data were in agreement with those reported in the literature. ${ }^{12}$ The compound turned brown with anisaldehyde on TLC.

Diuvaretin. The semipurified fraction containing diuvaretin was further purified by reverse-phase column chromatography (RP-2, $\mathrm{H}_{2} \mathrm{O}$ /acetone gradient) by fractogel chromatography (acetone) and by RP-PTLC (acetone $/ \mathrm{H}_{2} \mathrm{O}$ ). Weight: $36 \mathrm{mg}$. MS, ${ }^{1} \mathrm{H}$ NMR, UV, and IR data were in agreement with those reported in the literature. ${ }^{3}$ The compound turned pink with anisaldehyde on TLC.

Uvaretin. The semipurified fraction containing uvaretin was further purified by reverse-phase column chromatography (RP-2, $\mathrm{H}_{2} \mathrm{O}$ /acetone gradient) and recrystallized from benzene. Weight: $30 \mathrm{mg}$; mp $161-163^{\circ} \mathrm{C}$ (lit. ${ }^{3} \mathrm{mp} 164-165^{\circ} \mathrm{C}$ ). MS, ${ }^{1} \mathrm{H}$ NMR, UV, and IR were in agreement with those reported in the literature, and the compound turned pink with anisaldehyde on TLC.

$X$-ray Diffraction Analysis of Lucidene. The crystal structure of 1 was determined by X-ray diffraction. Crystal data: triclinic, space group $P \overline{1} ; a=9.417$ (5) $\AA, b=15.899$ (9) $\AA, c=$ 17.011 (8) $\AA, \alpha=69.96(4)^{\circ}, \beta=89.73(5)^{\circ}, \gamma=82.015(5)^{\circ} ; V$ $=2367 \AA^{3} ; Z=4 ; d_{\text {calc }}=1.17 \mathrm{~g} \mathrm{~cm}^{-3}, \mu=0.66 \mathrm{~cm}^{-1}$. Reflections were measured in the $\Omega / 2 \theta$ scan mode, using graphite monochromated Mo $\mathrm{K} \alpha$ radiation (scan width $(\Omega) 1.30+0.34 \tan \theta$ ). The structure was solved by direct methods and refined with full-matrix least-square methods. A total of 2691 reflections with $F_{0}{ }^{2}>3 \sigma\left(F_{0}{ }^{2}\right)$ was used in the refinement. The number of parameters refined was 435 (scale factor, positional and anisotropic thermal parameters for non $\mathrm{H}$ atoms, $\mathrm{H}$ atoms were treated as riding on their parent $\mathrm{C}$ atoms with fixed thermal parameters). The final $R$ factors were $R=5.6 \%$ and $R_{w}=5.9 \%$. All calculations were done with SDP. ${ }^{14}$ The unit cell contains two independent molecules with approximately the same conformation, one of which is shown in Figure 1.

Acknowledgment. We greatly appreciate the assistance of Dr. M. Posthumus (University of Wageningen), Dr. S. Wijmenga (NWO-NMR facilities, Nijmegen), Ing. A. Swolfs (University of Nijmegen), and Mr. T. Stevens (University of Twente) in obtaining spectra and Mr. L. B. Mwasumbi for identifying $U$. lucida spp. lucida. Part of this research was supported by a grant from the University of Dar es Salaam and by the NUFFIC-supported project of cooperation of the Universities of Nijmegen and Dar es Salaam.

Registry No. 1, 128216-79-5; uvaretin, 58449-06-2; diuvaretin, 61463-04-5; chamuvaretin, 64675-27-0.

Supplementary Material Available: Tables of positional and thermal parameters and bond distances and angles (11 pages). Ordering information is given on any current masthead page.

(14) Frenz, B. A. and Associates Inc., Structure Determination Package; College Station, TX, and Enraf-Nonius, Delft, 1983. 